\title{
A Two-Stage Approach to Integrate Vessel Geo-Tracking Data and Logbooks for Monitoring Fishing Activity of Coastal Fisheries in Waters off Northwestern Taiwan
}

Yi-Jou Lee

Department of Environmental Biology and Fisheries Science, National Taiwan Ocean University, Keelung, Taiwan

Nan-Jay Su

Center of Excellence for the Oceans, National Taiwan Ocean University, Keelung, Taiwan, nanjay@ntou.edu.tw

Cheng-Hsin Liao

Department of Environmental Biology and Fisheries Science, National Taiwan Ocean University, Keelung, Taiwan

Wei-Chuan Chiang

Eastern Marine Biology Research Center, Fisheries Research Institute, Council of Agriculture, Executive Yuan, Taitung, Taiwan

Chun-Huei Li

Fisheries Research Institute, Council of Agriculture, Executive Yuan, Keelung, Taiwan

Follow this and additional works at: https://jmstt.ntou.edu.tw/journal

Part of the Environmental Monitoring Commons, Marine Biology Commons, Natural Resources Management and Policy Commons, Ocean Engineering Commons, Oceanography Commons, and the Sustainability Commons

\section{Recommended Citation}

Lee, Yi-Jou; Su, Nan-Jay; Liao, Cheng-Hsin; Chiang, Wei-Chuan; and Li, Chun-Huei (2021) "A Two-Stage Approach to Integrate Vessel Geo-Tracking Data and Logbooks for Monitoring Fishing Activity of Coastal Fisheries in Waters off Northwestern Taiwan," Journal of Marine Science and Technology. Vol. 29: Iss. 4, Article 9.

DOI: $10.51400 / 2709-6998.1589$

Available at: https://jmstt.ntou.edu.tw/journal/vol29/iss4/9

This Research Article is brought to you for free and open access by Journal of Marine Science and Technology. It has been accepted for inclusion in Journal of Marine Science and Technology by an authorized editor of Journal of Marine Science and Technology. 
A Two-Stage Approach to Integrate Vessel Geo-Tracking Data and Logbooks for Monitoring Fishing Activity of Coastal Fisheries in Waters off Northwestern

Taiwan

Acknowledgements

Conflict of interest The authors declare that there is no conflict of interest. 


\title{
A Two-stage Approach to Integrate Vessel Geo-tracking Data and Logbooks for Monitoring Fishing Activity of Coastal Fisheries in Waters Off Northwestern Taiwan
}

\author{
Yi-Jou Lee ${ }^{a}$, Nan-Jay Su ${ }^{a, b, *}$, Cheng-Hsin Liao ${ }^{a, b}$, Wei-Chuan Chiang ${ }^{c}$, Chun-Huei Li ${ }^{d}$ \\ a Department of Environmental Biology and Fisheries Science, National Taiwan Ocean University, Keelung, 20224, Taiwan \\ ${ }^{\mathrm{b}}$ Center of Excellence for the Oceans, National Taiwan Ocean University, Keelung, 20224, Taiwan \\ ${ }^{\mathrm{c}}$ Eastern Marine Biology Research Center, Fisheries Research Institute, Council of Agriculture, Executive Yuan, Taitung, 96143, Taiwan \\ ${ }^{d}$ Fisheries Research Institute, Council of Agriculture, Executive Yuan, Keelung, 20246, Taiwan
}

\begin{abstract}
Catch and fishing effort data are fundamental information to stock assessment and fisheries management, but difficult to obtain without the support of administration and sound fishery data collection system. This study integrated various sources of data from a simplified vessel geo-tracking system and logbooks from interviews with captains of coastal gillnet fisheries. We developed a two-step approach based on hierarchical cluster analysis to characterize the operation patterns and infer the fishing activities of the fishery. Results showed that the fishing effort in terms of operation duration could be estimated precisely for various vessel sizes, with catch composition and harvest information from logbooks incorporated in the analysis. We then demonstrated how to monitor the geographical extent of fishing effort and the fishing intensity by vessel size and fishing season. The method developed in this study could benefit to understand the fleet dynamics and fishing pattern, and thus could potentially overcome the difficulty regarding to fisheries management due to the complexity of operation pattern in seasonal changes on target species and various strategies to fishing.
\end{abstract}

Keywords: Fleet dynamics, Fishing pattern, Vessel tracking, Cluster analysis

\section{Introduction}

$\mathrm{M}$ arine spatial planning (MSP) has become more and more important nowadays, and has been considered an effective management tool to compromise the utilization of marine areas and fisheries development [16]. Through the mapping of human activities and species interaction with fisheries, the implementation of MSP could potentially reduce the conflicts among authority, fishermen, developers, and stakeholders, and lower the impact on marine ecosystem function and services [8]. One of key elements to the success of MSP is the participation of various fishery sectors into the management framework. Several studies have demonstrated that management objectives may be difficult to achieve without the incorporation of fishery information into the decision making in multiple aspects of ecology, conservation, economy and society comprehensively $[5,15]$.

Information on catch and fishing effort is essential to stock assessment and fisheries management. However, it would be a challenge to obtain such information without the support of sound data collection system and administrative cooperation $[18,35]$. For example, data on operation duration are

Received 31 December 2019; revised 12 May 2020; accepted 30 June 2020.

Available online 3 September 2021.

* Corresponding author. Department of Environmental Biology and Fisheries Science, National Taiwan Ocean University, Keelung, 20224, Taiwan.

E-mail address: nanjay@ntou.edu.tw (N.-J. Su).

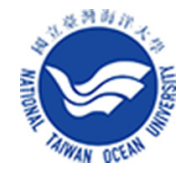


regarded as fundamental information to infer fishing effort for trawl and gillnet fisheries. Unfortunately, such kind of information is not always easy to reach, without the submission of logbook from captains $[12,13]$.

Development of vessel tracking technology based on geographic information system, such as vessel monitoring system (VMS) or automatic information system (AIS) serves as alternative approaches to understand operation characteristics, and thus could be used to estimate fishing effort in terms of fishing intensity and geographical extent [28,29]. Satellite-based geo-tracking systems can promptly provide near-time vessel position data to the administrative authority. However, high cost of data transmission and equipment installation prevents the popularization of this technique in, particularly, the coastal and inshore small-scale fisheries in Taiwan [6].

To implement fuel subsidy policies for fishing vessels, an alternative simplified geo-tracking device, called voyage data recorder (VDR), is developed and forced to be installed in vessels larger than 20 GRT in Taiwan. This approach can provide high resolution data on vessel position, speed, and heading angle at $3 \mathrm{~min}$ intervals, which forms the basis to characterize operation patterns and infer the fishing activities at sea for fishing vessel fuel subsidies (see [7]. However, little studies have focused on the application of this source of information to derive spatial distribution and intensity of fishing effort, combining with logbooks and catch reports, for assessment and fisheries management purposes.

The objectives of this study were to integrate two sources of data from VDR and logbooks based on vessel tracking technology and interviews with captains from a coastal and inshore gillnet fishery in waters off northwestern Taiwan. Fishing trips with information available on VDR, operation characteristics, and catch composition were classified by group to infer the fishing intensity and spatial

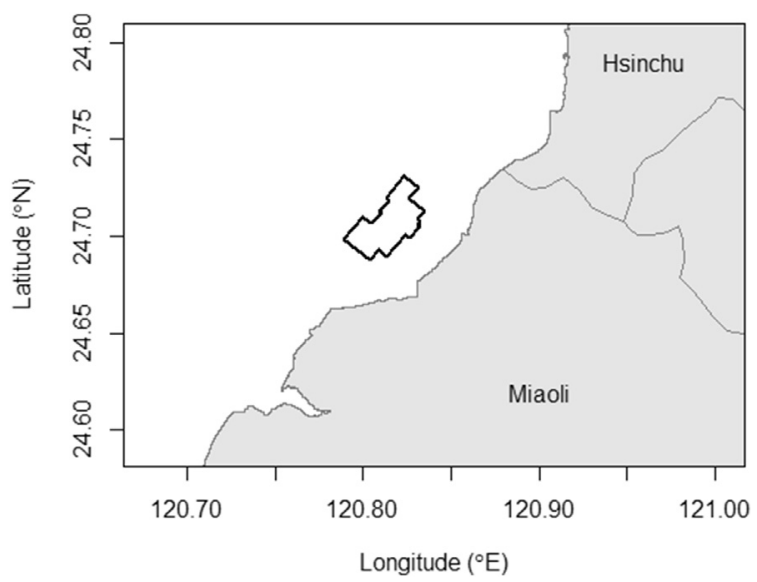

Fig. 1. Map showing the study area and the location of the offshore wind farm off northwestern Taiwan.

distribution of the effort. Results derived from the analysis were presented by vessel size and fishing season, which aims to provide basic scientific knowledge as management tools to effectively monitor the fleet dynamics and fishing pressure for small-scale fisheries.

\section{Materials and methods}

\subsection{Data collection}

The study area off northwestern Taiwan $\left(120.7-121.0^{\circ} \mathrm{E}\right.$ and $\left.24.6-24.8^{\circ} \mathrm{N}\right)$ is shown in Fig. 1, where the Formosa 1: the Taiwan's first commercialscale offshore wind farm is located. The coastal gillnets is the major fishery in this area; however, they may suffer the impact of turbine operation during the demonstration phase. Two data sets relating to this fishery were therefore collected for analysis (Table 1 ).

We collected VDR data for auxiliary information and comparison with logbooks. VDR is a fishery management system widely used in Taiwan to monitor the fleet dynamics of coastal and inshore fisheries, which provides information of vessel

Table 1. Summary table for the two data sets used in the analysis.

\begin{tabular}{lll}
\hline Source & Variable & Description \\
\hline Logbook & Vessel & Registered number of fishing vessel to link with VDR \\
& Date & Operation date \\
& Latitude & Operation location in latitude \\
& Longitude & Operation location in longitude \\
& Catch & Landing by species in weight (kg) \\
& Size & Vessel size in GRT categorized using 5 levels: CTR (fishing raft), \\
& CT0 $(<5$ GRT), CT1 (5-10 GRT), CT2 (10-20 GRT), CT3 (20-50 GRT), CT4 (50-100 GRT) \\
VDR & Vessel & Registered number of fishing vessel \\
& Speed & Reported location in latitude \\
& Latitude & Reported location in longitude \\
\hline
\end{tabular}


location every $3 \mathrm{~min}$. Data from this system could be used to estimate the fishing effort in terms of duration and location for each registered vessel. However, the VDR information consists of both vessel cruising and operating, and the data need to be separated to present the fishing effort correctly. Methods based on speed criterion to define fishing activities have been demonstrated in numerous previous studies (e.g., [2,3,22]. A speed criterion following [14] was applied by vessel size to infer the fishing effort in hours and distribution of fishing intensity by spatial grid in $1 \mathrm{~min}$ for this coastal gillnet fishery in this study.

Fishing vessels larger than 20 GRT are forced to install VDR system in Taiwan, but this is not mandatory for small coastal and inshore fishing vessels. Even so, some captains show their willing to be volunteers and provide voyage information to the management system. We collected VDR data for vessels operating in coastal waters off northwestern Taiwan (Fig. 1) for potential evaluation of impacts from offshore wind farms on the marine ecosystem and fishery resources. In addition, through interview with captains, logbooks were collected at major fishing ports every month from 2013 to 2017, which include information on fishing date, operation location in latitude and longitude, operating hours (starting and ending time) and species caught in weight and/or number. We then matched the VDR data with logbooks to cross validate the information from two sources, in order to better estimate the fishing effort with associated harvest and location.

\subsection{Data analysis}

Due to complexity of coastal and inshore fisheries, such as seasonal targeting shifts and changes in fishing strategy and operation patterns, a hierarchical cluster analysis (HCA) was applied to group the fishing trips according to vessel sizes (tonnage) and operation location in latitude and longitude of the fishing effort. HCA was used once again to separate the fishing season by trip group determined at the first HAC based on monthly targeting shift and catch composition in species. This twostage based approach could substantially benefit the understanding of fishing strategy and fleet dynamics over time and through the fishing ground $[17,21,30]$.

The HCA was conducted using "hclust" function in software R [25] based on the Gower distance [9] and Ward's grouping algorithm [33]. The optimal number of clusters was determined based on the Elbow method. Spatial distributions of fishing effort were accordingly mapped by vessel size and fishing season for each year from 2013 to 2017 to examine the annual variation. Fishing intensity and catch amount from the coastal gillnet fishery were also plotted by vessel size and season to further examine the shift in fishing effort associated with fishing strategy and resulted changes in catch composition.

\section{Results}

In total, 911 fishing trips with operation location and reported catch information from 116 gillnet vessels were separated into 3 groups based on hierarchical cluster analysis (Fig. 2). Fishing vessels smaller than 5 GRT (as known as vessel classification in Taiwan, CTR) were assigned to the first group, while the other two groups consist of vessels between 5 and 100 GRT (vessel classification CR1 to CT4). Very few fishing trips for the vessels larger than 5 GRT $(<0.5 \%)$ were grouped into the first group based on operation location and catch

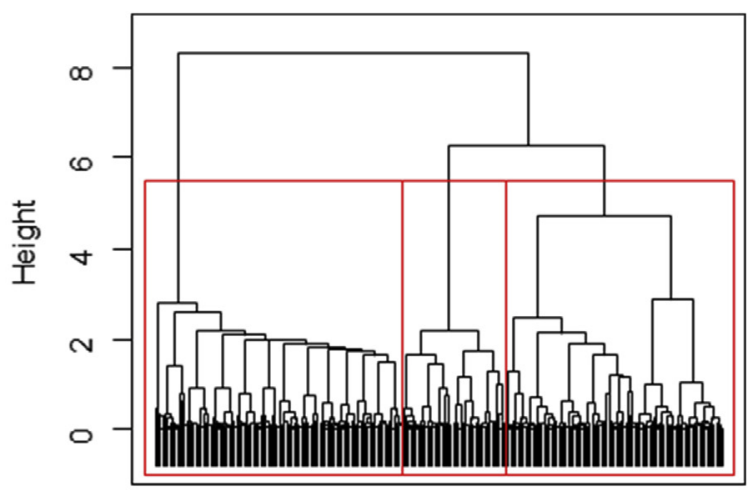

Fishing trip

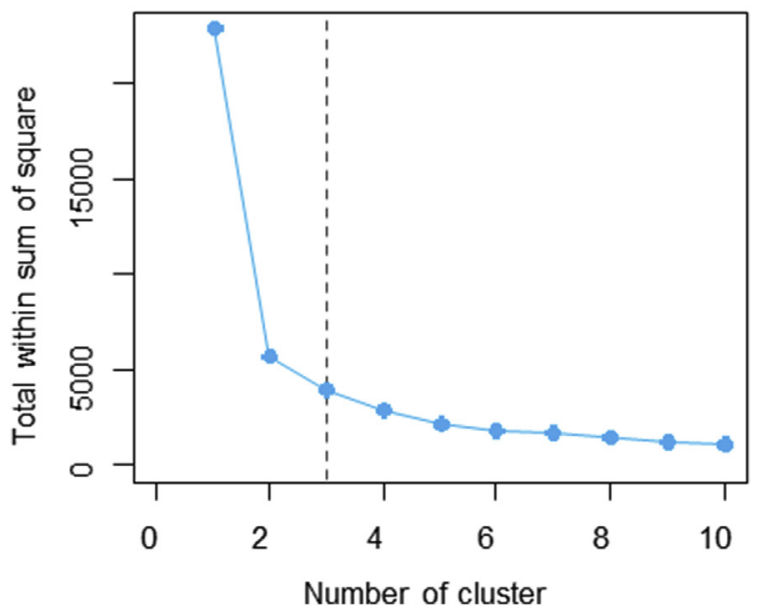

Fig. 2. Hierarchical cluster dendrogram to group the fishing trips of a small-scale gillnet fishery in coastal and inshore waters off northwestern Taiwan (top panel), and the criterion information shown by number of cluster used to determine suitable groups using the Elbow method, as indicated by the vertical dashed line (bottom panel). 

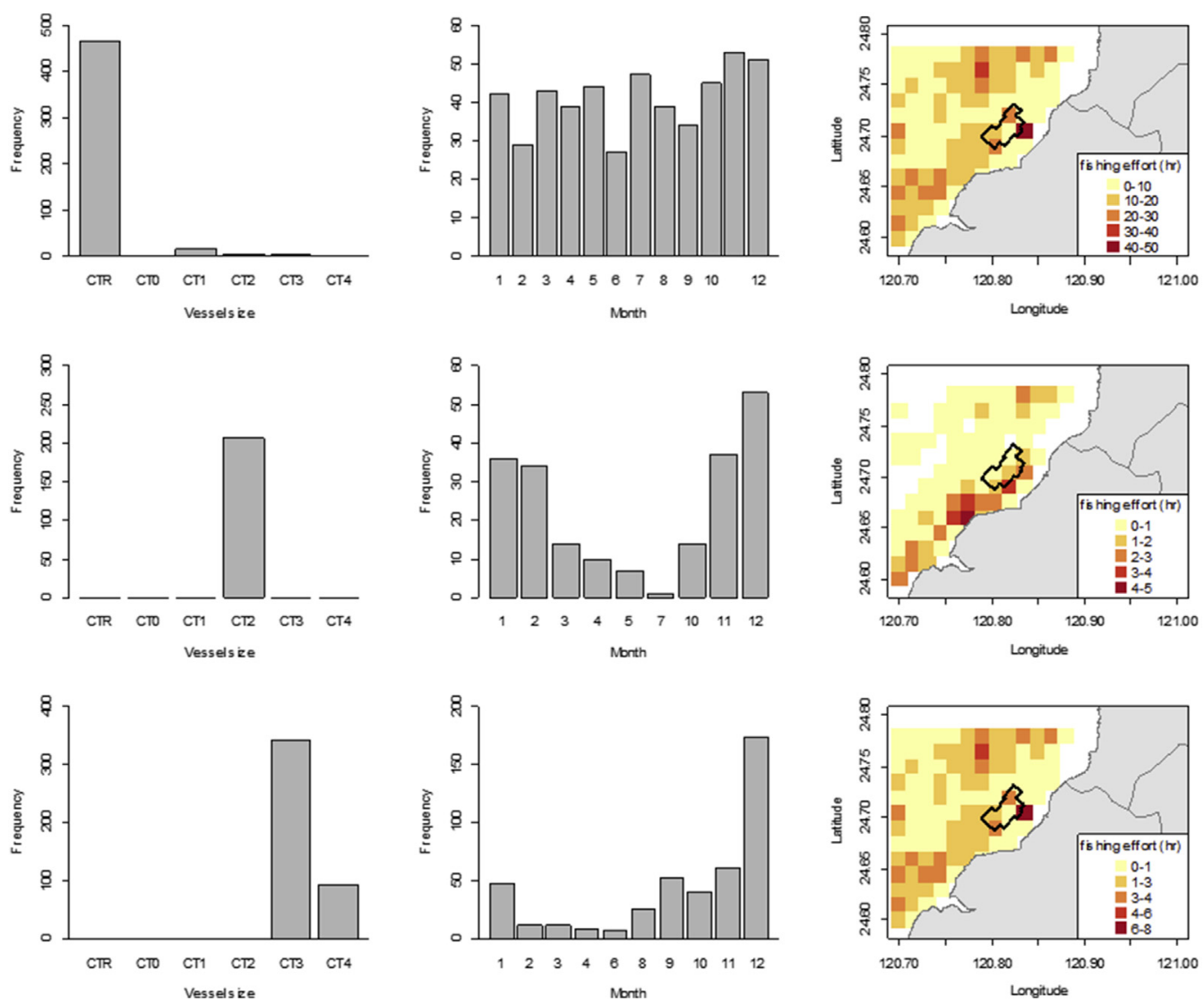

Fig. 3. Numbers of fishing trip by vessel size (left panels) and month (middle panels) for various vessel sizes grouped by hierarchical cluster analysis (from top to bottom). The spatial distributions of fishing effort and the area of offshore wind farm are shown in the maps (right panels).

composition information (Fig. 3). The small fishing vessels $(<5$ GRT) mainly operated around the area of offshore wind farm, but large vessels fished in two major fishing grounds northern and southern the wind farm area (see right panels in Fig. 3). The small-scale coastal gillnet fishery was therefore divided into 3 categories according to the vessel size.

The hierarchical cluster analysis was applied once again to determine the fishing season for each vessel size class. Three fishing seasons (summer, spring, and winter) were found for the small fishing vessels ( $<5$ GRT), while two fishing seasons (March-October and November to the next February) were shown for the vessels between 5 and 20 GRT (Fig. 4). However, December, besides the two major fishing season, were decided for the large fishing vessels (20-100 GRT) operating in this area owing to the seasonal change in catch composition. In that season (December), large amount of mullet (Mugil cephalus; $98 \%$ ) was caught by the vessels larger than 20 GRT (Table 2). Sharks, bonitos, and seer fish (i.e., Scomberomorus commerson and Scomberomorus niphonius) were the main harvest from February to November. For fishing vessels between 5 and 20 GRT, sharks and mullets were major catch for summer fishing season (March-October) and the winter (November to February), respectively. A variety of harvest species, including cephalopod $(23 \%)$, mullet $(16 \%)$, croaker $(14 \%)$, stingray $(13 \%)$, and sea bream $(11 \%)$ were caught by small fishing vessels during the three different fishing seasons (Table 2).

In general, the small fishing vessels operated around the area of offshore wind farm during various fishing seasons. They fished in the southern part of the coastal waters from 2015 to 2017. Seasonal variation in fishing effort distribution was not evident for the small vessels (Fig. 5). However, the major harvest species varied seasonally, from cephalopod and stingray in spring, croaker in summer, and mullet and sea bream in winter (Table 2). For vessels between 5 and 20 GRT, spatial distributions of fishing effort changed seasonally and decreased year by year (Fig. 6). Sharks and mullets were the dominant species in summer and winter, respectively. The spatial distributions of fishing effort for fishing vessels larger than 20 GRT differed seasonally. Fishing intensity was low between January and August, increased from September to 

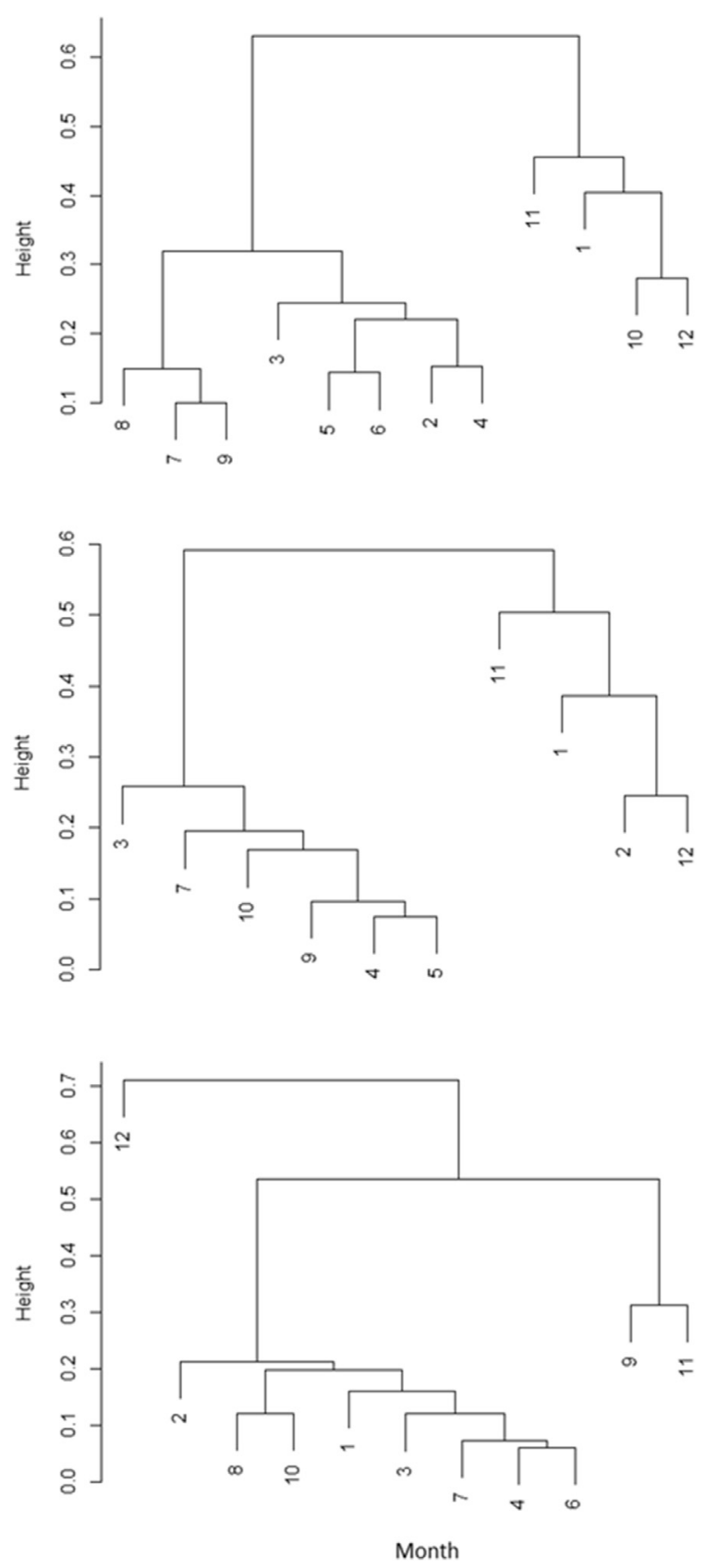

Fig. 4. Hierarchical cluster analysis to group the fishing trips by month, which is used to determine the fishing season for various vessel sizes of the small-scale gillnet fishery in coastal and inshore waters off northwestern Taiwan.

November, and reached a maximum in December (Fig. 7). Sharks were the major species harvested by the large vessels from February to November, but large amount of seer fish caught in fall and mullets dominate the catch in December for vessels larger than 20 GRT (Table 2).

The fishing effort remained relatively stable during 2013-2017 for small fishing vessels operating in coastal and inshore waters off northwestern Taiwan, and the catch showed a slightly decreasing trend during the same time, except for 2017 with high catch around $4 \mathrm{mt}$ (Fig. 8). Different patterns were shown for vessels between 5 and 20 GRT. Annual variation was higher in the first fishing season than the second. Extremely high fishing effort and resulted catch presented in 2015, but decreased thereafter from November to near the next February). In contrast, the fishing effort for large vessels increased year by year, with the mullet catch dramatically reached to around $60 \mathrm{mt}$ in 2014 and decreased thereafter to 2017 (Fig. 8).

\section{Discussion}

The need to reduce fishing pressure for coastal and inshore fisheries has been raised urgently in recent years due to overexploitation of fishery resources and degradation of marine ecosystem. However, adequate management for the small-scale artisanal fisheries is always not an easy task because a large number (more than 10,000) fishing vessels operate in complex fishing strategies in waters around Taiwan. For example, the fishermen may use various mesh sizes of gillnets to target different species by season in a so-called single coastal or inshore fishery, resulting in bias estimates of fishing intensity potentially. To overcome this, a two-stage quantitative approach combining hierarchical cluster analysis was demonstrated to be able to regularly monitor the fishing activity and fleet dynamics by vessel size and fishing season (operating strategy) based on VMS and logbook data combining.

Many studies have used vessel position data (VMS or VDR) to resolve the fishing activities at a higher spatial and temporal resolution, and precisely estimate the fishing effort (e.g., [10,34]. However, most of them were carried out for trawlers, and relative few ones aim to analyze data for other fisheries, such as gillnets. This is probably because the speed of trawling remains relatively constant when operating, making them easy to predict the fishing behavior. In contrast, the speed characteristics of gillnet fishery, as those in present study, could be complicated during the steaming to fishing grounds and multiple phases of setting and retrieving under the current condition that may impact the speed of vessel. Results from this study showed that the fishing effort could be determined correctly when the location to shore and the time after leaving the fishing port were served as vessel speed criteria in the analysis [26].

Effectively monitoring fishing effort in small-scale fisheries is essential and vital to understanding their 
Table 2. Summary of major catch species from a small-scale gillnet fishery in coastal and inshore waters off northwestern Taiwan. Information is shown for three vessels sizes and different fishing season identified by hierarchical cluster analysis. The numbers in parenthesis indicate the percentage of total catch in weight.

\begin{tabular}{|c|c|c|c|c|c|}
\hline Vessel size & $<5$ GRT & & 5-20 GRT & & 20-100 GRT \\
\hline Class & CTR, CT0 & & CT1, CT2 & & CT3, CT4 \\
\hline Fishing & Major & Fishing & Major & Fishing & Major \\
\hline season & catch $(\%)$ & season & catch $(\%)$ & season & catch $(\%)$ \\
\hline February-June & $\begin{array}{l}\text { Cephalopod (23) } \\
\text { Stingray (13) } \\
\text { Sea bream (7) } \\
\text { Croaker (6) } \\
\text { Shark (5) }\end{array}$ & March-October & $\begin{array}{l}\text { Shark (34) } \\
\text { Seer fish (10) } \\
\text { Cephalopod (6) } \\
\text { Grouper (5) } \\
\text { Stingray (4) }\end{array}$ & January-August & $\begin{array}{l}\text { Shark (30) } \\
\text { Bonito (12) } \\
\text { Seer fish (7) } \\
\text { Stingray (6) } \\
\text { Tuna (2) }\end{array}$ \\
\hline July-September & $\begin{array}{l}\text { Croaker (14) } \\
\text { Scad (8) } \\
\text { Stingray (5) } \\
\text { Sea bream (5) } \\
\text { Mackerel (2) }\end{array}$ & November-February & $\begin{array}{l}\text { Mullet (42) } \\
\text { Anchovy (9) } \\
\text { Seer fish (9) } \\
\text { Bonito (8) } \\
\text { Pomfret (5) }\end{array}$ & September-November & $\begin{array}{l}\text { Shark (30) } \\
\text { Seer fish (26) } \\
\text { Bonito (8) } \\
\text { Scad (7) } \\
\text { Anchovy (5) }\end{array}$ \\
\hline October-January & $\begin{array}{l}\text { Mullet (16) } \\
\text { Sea bream (11) } \\
\text { Croaker (6) } \\
\text { Scad (4) } \\
\text { Bonito (3) }\end{array}$ & & & December & $\begin{array}{l}\text { Mullet (98) } \\
\text { Scad (0.3) } \\
\text { Bonito }(0.2) \\
\text { Pomfret }(0.2) \\
\text { Hairtail }(0.1)\end{array}$ \\
\hline
\end{tabular}

impacts on fish stocks and marine ecosystems. There are several approaches available in the literature, among which the analysis of logbook data is the commonest method to estimate the fishing intensity (e.g., [31,32]. However, approaches based on logbooks solely are intrinsically limited by several drawbacks. For example, logbooks are not always available sources of data if there is no mandatory regulation to enforce fishermen to submit operation reports. Even so fishermen submitting the records, the information from logbooks may be insufficient to reflect details in terms of fishing intention and behavior, and thus it may be difficult to infer the fishing intensity and effort distribution of the vessel operating [19].

It was shown as an efficient way to combine data sources from vessel tracking data and logbooks and integrate in analysis to validate the estimate of fishing effort in terms of operation duration for fishing trips. Consistency was found in this study for the fishing effort derived from vessel position and verified by logbooks. However, this is based on reference points in operation time and location to be identified from the VDR data, and then used to infer the fishing activity. In agreement with previous studies, approaches that incorporate various types of data sources could estimate fishing effort and intensity successfully (e.g., [1,4]. As such, this study suggests that information from alternative sources, other than VMS or VDR, should be available, such as gear used and landing receipts when this approach was applied to other fisheries. In addition, publicly accessible vessel tracking systems (e.g., satellite-based automatic identification system) serve as another potential source of data to infer the fishing effort for fisheries management and marine planning in the future as suggested by [20].

Previous studies of fishing activities in small-scale fisheries have been usually based on interviews with fishermen. However, limited by short duration of survey or insufficient spatial resolution of vessel location, these approaches provide imprecise information in determining fishing effort [23]). VMS/ VDR was thus developed to be used for monitoring fishing activity, and has increasingly been applied in fisheries management and ecology research in recent years owing to the advantage of being immediately available precisely and continuously for a long-term of monitoring fishing effort at a finer spatial and temporal resolution $[19,24]$.

Another issue to be addressed is the technology to integrate vessel position data and catch information from logbooks because there is no direct way or system to collect catch and effort data simultaneously. Catch reports from this small-scale fishery may be assigned to a fishing location uncertainly because the fishermen could operate more than once during a single fishing day by coming back to the fishing ground again for good harvest. Therefore, it is important to identify fishing activity from non-fishing movements and allocate catch to separate operation location in multiple trip scenarios. We successfully applied a set of criteria to the vessel tracking data for filtering the fishing ground. Results could be improved and refined by means of spatial models or artificial intelligence technique to 


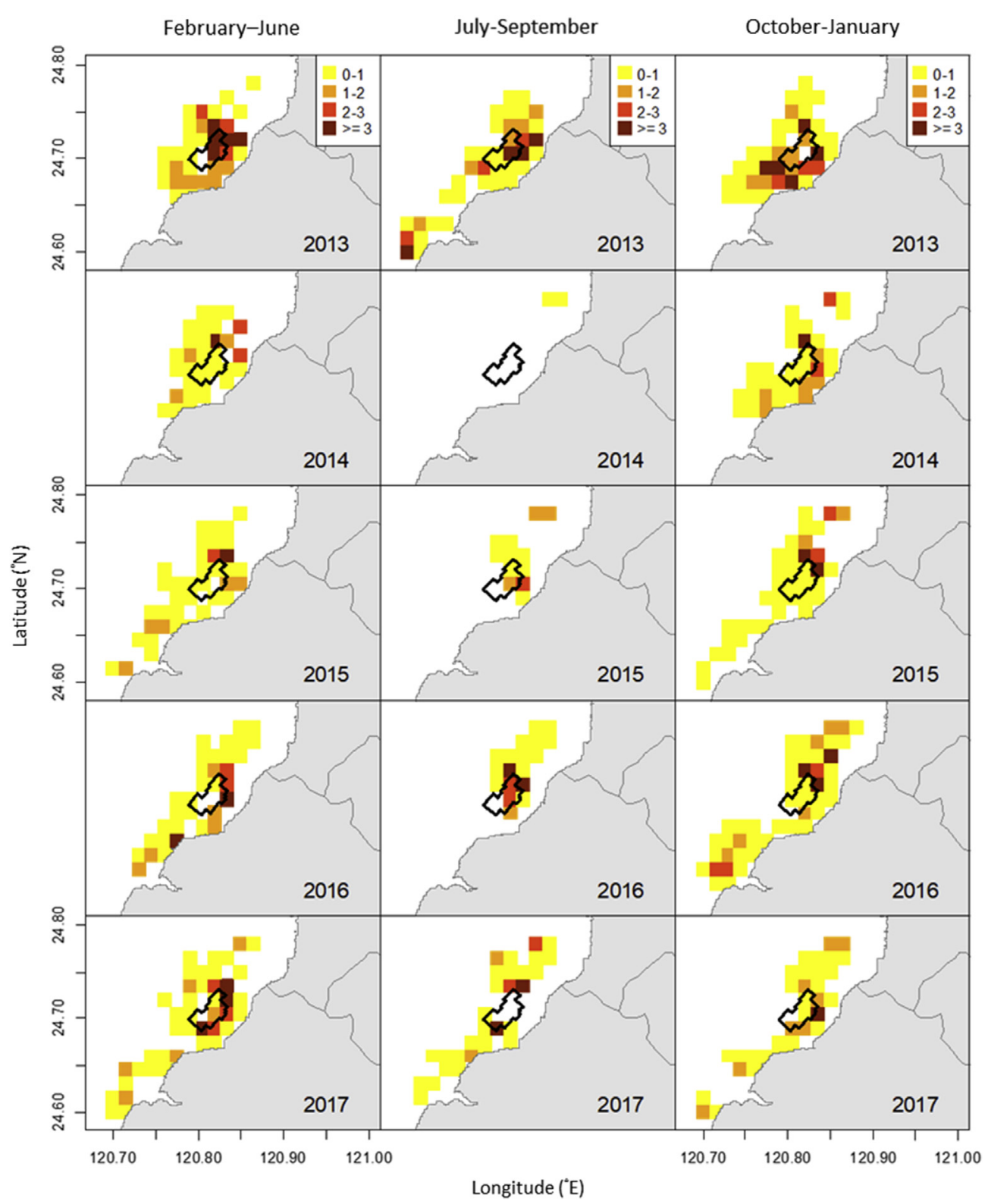

Fig. 5. Spatial distributions of fishing effort by fishing season (left to right) for small vessels ( $<5$ GRT) of a small-scale gillnet fishery in coastal and inshore waters off northwestern Taiwan. The area of offshore wind farm is shown in the maps. 


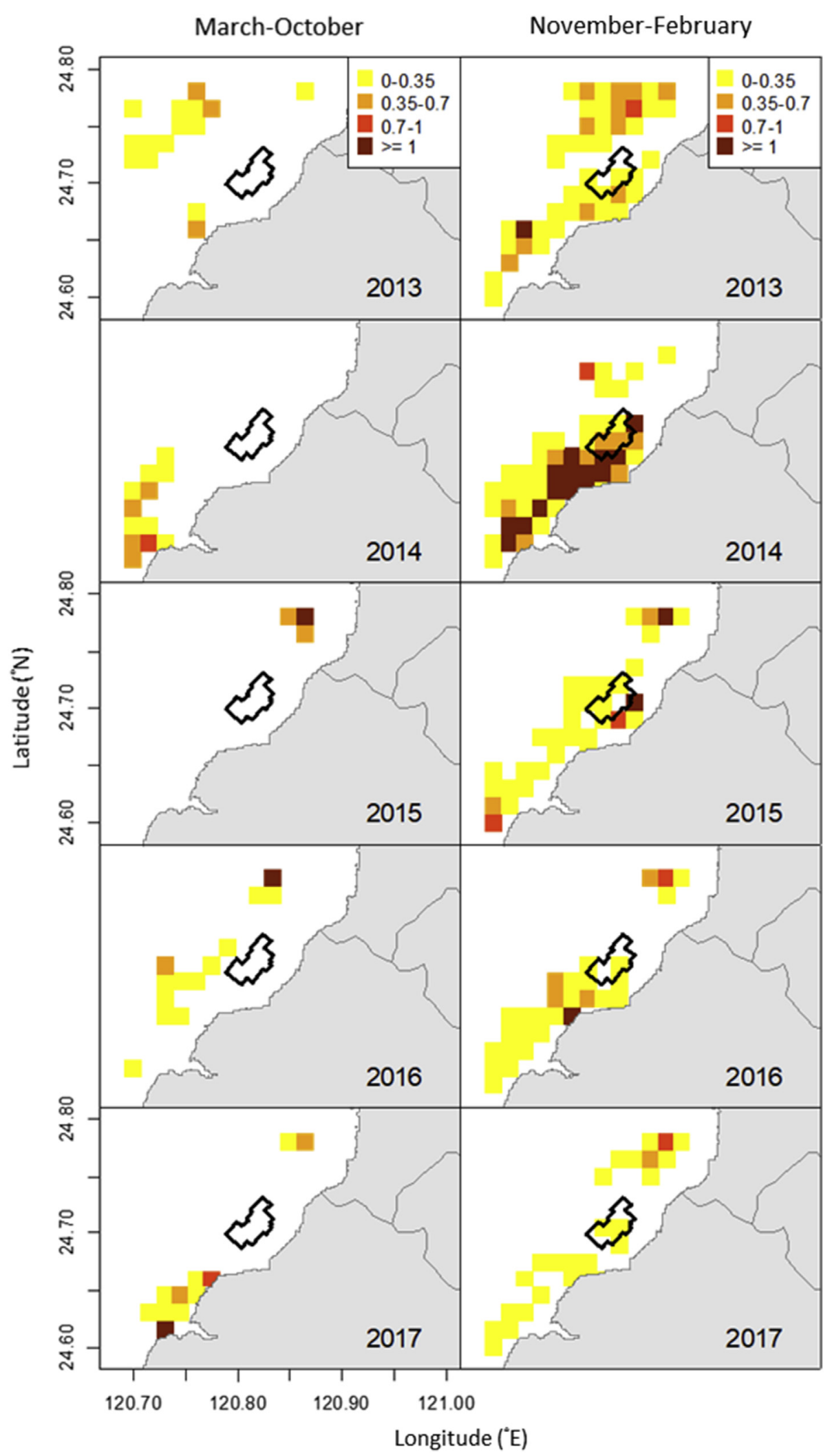

Fig. 6. Spatial distributions of fishing effort by fishing season (left to right) for vessels between 5 and 20 GRT of a small-scale gillnet fishery in coastal and inshore waters off northwestern Taiwan. The area of offshore wind farm is shown in the maps. 


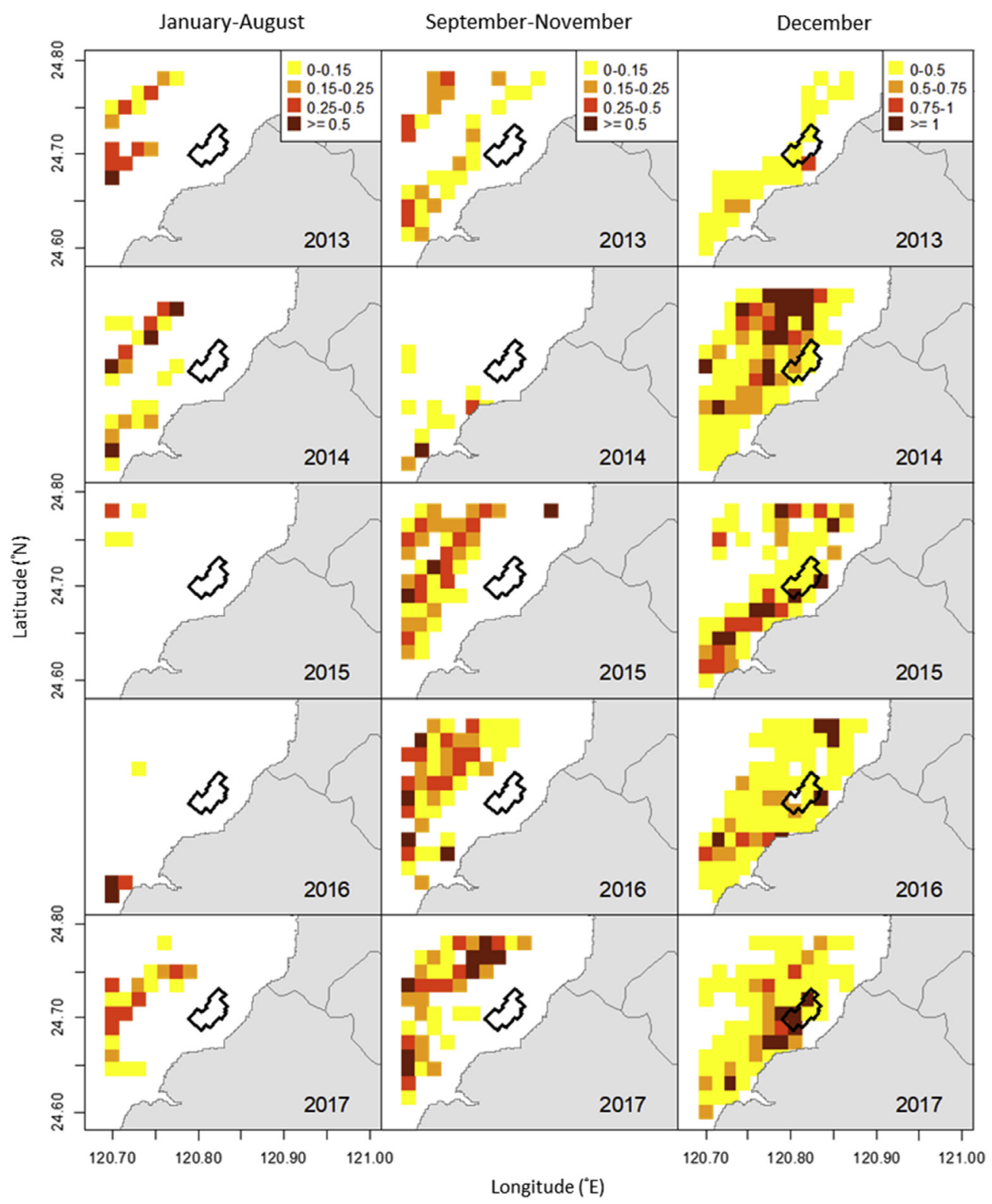

Fig. 7. Spatial distributions of fishing effort by fishing season (left to right) for vessels between 20 and 100 GRT of a small-scale gillnet fishery in coastal and inshore waters off northwestern Taiwan. The area of offshore wind farm is shown in the maps. 

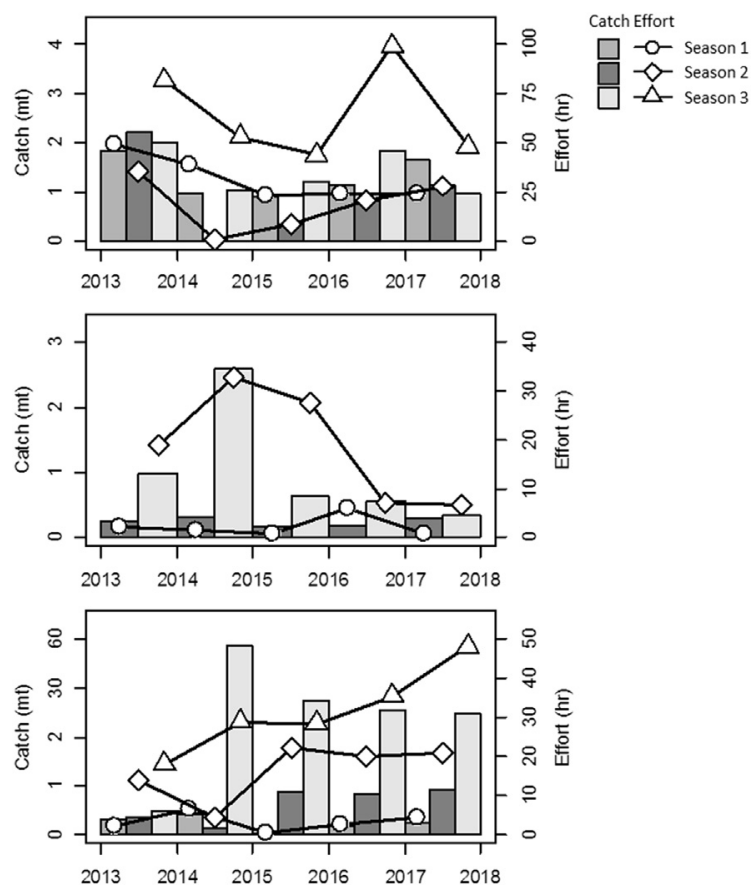

Fig. 8. Catch in weight (mt; bars) and fishing effort (hr; lines and open points) shown by fishing season for various vessel sizes (top: $<5$ GRT; middle: 5-20; bottom: 20-100) grouped by hierarchical cluster analysis. Note that the definition of fishing season differs among vessel sizes (see Table 2).

differentiate vessel tracks where fishing gears are being deployed. The approaches implemented by $[11,27]$ were demonstrated as cases to reduce error rates in characterizing fishing trips efficiently.

In conclusion, characterizing fishing activity and using them to inform fishery indicators (CPUE) represents a challenge in fisheries science since logbooks and vessel tracking technology is still developing. In the present study, we proposed a cost-effective method to monitor seasonal patterns in fishing effort and targeting changes for a smallscale fishery. With modifications by incorporating cluster analysis, one could expect that this approach to be used to overcome some deficiencies in logbooks or reports by fishermen and observers.

\section{Conflict of interest}

The authors declare that there is no conflict of interest.

\section{Acknowledgements}

We thank the comments and suggestions from the reviewer and the editor, which improve the initial version of this manuscript. We also would like to acknowledge the financial support by Fisheries Research Institute, Council of Agriculture, Executive
Yuan in funding for this work by the research projects (109AS-20.2.1-AI-A4 and 110AS-6.1.2-FAF2(1)). Special thanks are given to the research team in the National Taiwan Ocean University and Fisheries Research Institute of Council of Agriculture for sample collection and field survey under the support of the research project.

\section{References}

[1] Alexander KE, Leavenworth WB, Cournane J, Cooper AB, Claesson S, Brennan S, et al. Gulf of Maine cod in 1861: historical analysis of fishery logbooks, with ecosystem implications. Fish Fish 2009;10:428-49.

[2] Baker Jr MS, Sciance MB, Halls JN. Potential for a simple GPS-based binary logit model to predict fishing effort in a vertical hook-and-line reef fish fishery. Marine Coastal Fish 2016;8:118-31.

[3] Bastardie F, Nielsen JR, Ulrich C, Egekvist J, Degel H. Detailed mapping of fishing effort and landings by coupling fishing logbooks with satellite-recorded vessel geo-location. Fish Res 2010;106:41-53.

[4] Bellman MA, Heppell SA, Goldfinger C. Evaluation of a US west coast groundfish habitat conservation regulation via analysis of spatial and temporal patterns of trawl fishing effort. Can J Fish Aquat Sci 2005;62:2886-900.

[5] Berghöfer A, Wittmer H, Rauschmayer F. Stakeholder participation in ecosystem-based approaches to fisheries management: a synthesis from European research projects. Mar Pol 2008;32:243-53.

[6] Chang SK. From subsidy evaluation to effort estimation: advancing the function of voyage data recorders for offshore trawl fishery management. Mar Pol 2016;74:99-107.

[7] Chang SK, Liu HI, Fukuda H, Maunder MN. Data reconstruction can improve abundance index estimation: an example using Taiwanese longline data for Pacific bluefin tuna. PloS One 2017;12:e0185784.

[8] Douvere F, Ehler CN. New perspectives on sea use management: initial findings from European experience with marine spatial planning. J Environ Manag 2009;90:77-88.

[9] Gower JC. A general coefficient of similarity and some of its properties. Biometrics 1971;27:857-71.

[10] James M, Mendo T, Jones EL, Orr K, McKnight A, Thompson J. AIS data to inform small scale fisheries management and marine spatial planning. Mar Pol 2018;91: 113-21.

[11] Johnson AF, Moreno-Báez M, Giron-Nava A, Corominas J, Erisman B, Ezcurra E, et al. A spatial method to calculate small-scale fisheries effort in data poor scenarios. PloS One 2017;12:e0174064.

[12] Le Pape O, Delavenne J, Vaz S. Quantitative mapping of fish habitat: a useful tool to design spatialised management measures and marine protected area with fishery objectives. Ocean Coast Manag 2014;87:8-19.

[13] Le Tixerant M, Le Guyader D, Gourmelon F, Queffelec B. How can Automatic Identification System (AIS) data be used for maritime spatial planning? Ocean Coast Manag 2018;166: 18-30.

[14] Liao CH, Huang HT. Analysis of Taiwan coastal and offshore fisheries activities. In: Report of research project. Kaohsiung, Taiwan: Fisheries Agency; 2018. p. 157 (In Chinese).

[15] Liu WH, Wu CC, Jhan HT, Ho CH. The role of local government in marine spatial planning and management in Taiwan. Mar Pol 2011;35:105-15.

[16] Maes F. The international legal framework for marine spatial planning. Mar Pol 2008;32:797-810.

[17] Mahévas S, Bellanger L, Trenkel VM. Cluster analysis of linear model coefficients under contiguity constraints for identifying spatial and temporal fishing effort patterns. Fish Res 2008;93:29-38. 
[18] Mangi SC. The impact of offshore wind farms on marine ecosystems: a review taking an ecosystem services perspective. Proc IEEE 2013;101:999-1009.

[19] McCluskey SM, Lewison RL. Quantifying fishing effort: a synthesis of current methods and their applications. Fish Fish 2008;9:188-200.

[20] Mendo T, Smout S, Photopoulou T, James M. Identifying fishing grounds from vessel tracks: model-based inference for small scale fisheries6. Royal Society Open Science; 2019. p. 191161.

[21] Monroy C, Salas S, Bello-Pineda J. Dynamics of fishing gear and spatial allocation of fishing effort in a multispecies fleet. N Am J Fish Manag 2010;30:1187-202.

[22] Natale F, Gibin M, Alessandrini A, Vespe M, Paulrud A. Mapping fishing effort through AIS data. PloS One 2015;10: e0130746.

[23] O'Farrell SO, Sanchirico JN, Chollett I, Cockrell M, Murawski SA, Watson JT, et al. Improving detection of shortduration fishing behaviour in vessel tracks by feature engineering of training data. ICES (Int Counc Explor Sea) J Mar Sci 2017;74:1428-36.

[24] Palmer MC, Demarest C. Getting to good enough: performance of a suite of methods for spatially allocating fishing effort to management areas. Fish Res 2018;204:26-32.

[25] R Core Team. R: a language and environment for statistical computing. Vienna, Austria: R Foundation for Statistical Computing; 2018.

[26] Rezende GA, Rufener M-C, Ortega I, Ruas VM, Dumont LFC. Modelling the spatio-temporal bycatch dynamics in an estuarine small-scale shrimp trawl fishery. Fish Res 2019;219:105336.

[27] Russo T, Parisi A, Prorgi M, Boccoli F, Cignini I, Tordoni M, et al. When behaviour reveals activity: assigning fishing effort to métiers based on VMS data using artificial neural networks. Fish Res 2011;111:53-64.
[28] Stelzenmüller V, Diekmann R, Bastardie F, Schulze $T$, Berkenhagen J, Kloppmann M, et al. Co-location of passive gear fisheries in offshore wind farms in the German EEZ of the North Sea: a first socio-economic scoping. J Environ Manag 2016;183:794-805.

[29] Trouillet B, Bellanger-Husi L, El Ghaziri A, Lamberts C, Plissonneau E, Rollo N. More than maps: providing an alternative for fisheries and Fishers in marine spatial planning. Ocean Coast Manag 2019;173:90-103.

[30] Tzanatos E, Dimitriou E, Katselis G, Georgiadis M, Koutsikopoulos C. Composition, temporal dynamics and regional characteristics of small-scale fisheries in Greece. Fish Res 2005;73:147-58.

[31] Walsh WA, Kleiber P, McCracken M. Comparison of logbook reports of incidental blue shark catch rates by Hawaii-based longline vessels to fishery observer data by application of a generalized additive model. Fish Res 2002;58 79-94.

[32] Walsh WA, Ito RY, Kawamoto KE, McCracken M. Analysis of logbook accuracy for blue marlin (Makaira nigricans) in the Hawaii-based longline fishery with a generalized additive model and commercial sales data. Fish Res 2005;75:175-92.

[33] Ward JH. Hierarchical grouping to optimize an objective function. J Am Stat Assoc 1963;58:236-44.

[34] Watson JT, Haynie AC, Sullivan PJ, Perruso L, O'Farrell S, Sanchirico JN, et al. Vessel monitoring systems (VMS) reveal an increase in fishing efficiency following regulatory changes in a demersal longline fishery. Fish Res 2018;207: 85-94.

[35] Zhang Y, Zhang C, Chang YC, Liu WH, Zhang Y. Offshore wind farm in marine spatial planning and the stakeholders engagement: opportunities and challenges for Taiwan. Ocean Coast Manag 2017;149:69-80. 